\title{
Protoporphyrin IX enhancement by 5-aminolaevulinic acid peptide derivatives and the effect of RNA silencing on intracellular
} metabolism

\author{
L Bourré', F Giuntini', IM Eggleston'2, M Wilson ${ }^{3}$ and AJ MacRobert ${ }^{*, 1}$ \\ 'Division of Surgical and Interventional Sciences, National Medical Laser Centre, UCL Medical School, University College London, Charles Bell House, \\ 67-73 Riding House St, London WIW 7EJ, UK; ${ }^{2}$ Department of Pharmacy and Pharmacology, University of Bath, Claverton Down, Bath BA2 7AY, UK; \\ ${ }^{3}$ Division of Microbial Diseases, UCL Eastman Dental Institute, University College London, 256 Grays Inn Road, London WCIX 8LD, UK
}

\begin{abstract}
Intracellular generation of the photosensitiser, protoporphyrin IX, from a series of dipeptide derivatives of the haem precursor, 5-aminolaevulinic acid (ALA), was investigated in transformed PAM2I2 murine keratinocytes, together with studies of their intracellular metabolism. Porphyrin production was substantially increased compared with equimolar ALA using N-acetyl terminated phenylalanyl, leucinyl and methionyl ALA methyl ester derivatives in the following order: Ac-L-phenylalanyl-ALA-Me, AC-L-methionylALA-Me and Ac-L-leucinyl-ALA-Me. The enhanced porphyrin production was in good correlation with improved photocytotoxicity, with no intrinsic dark toxicity apparent. However, phenylalanyl derivatives without the acetyl/acyl group at the $\mathrm{N}$ terminus induced significantly less porphyrin, and the replacement of the acetyl group by a benzyloxycarbonyl group resulted in no porphyrin production. Porphyrin production was reduced in the presence of class-specific protease inhibitors, namely serine protease inhibitors. Using siRNA knockdown of acylpeptide hydrolase (ACPH) protein expression, we showed the involvement of $\mathrm{ACPH}$, a member of the prolyl oligopeptidase family of serine peptidases, in the hydrolytic cleavage of ALA from the peptide derivatives. In conclusion, ALA peptide derivatives are capable of delivering ALA efficiently to cells and enhancing porphyrin synthesis and photocytotoxicity; however, the $\mathrm{N}$-terminus state, whether free or substituted, plays an important role in determining the biological efficacy of ALA peptide derivatives.
\end{abstract}

British Journal of Cancer (2009) 100, 723-731. doi:10.1038/sj.bjc.6604928 www.bjcancer.com

Published online 24 February 2009

(c) 2009 Cancer Research UK

Keywords: photodynamic therapy; aminolaevulinic acid; ALA derivatives; acylpeptide hydrolase (ACPH, EC 3.4.19. I); siRNA silencing; protoporphyrin IX

Photodynamic therapy (PDT) is a promising modality for cancer treatment that utilises tumour-specific accumulation of a photosensitiser, followed by irradiation with light at an appropriate wavelength (Bonnett, 1995). The use of 5-aminolaevulinic acid (ALA) for PDT has received considerable interest owing to the metabolism of ALA through the haem biosynthetic pathway (Peng et al, 1997) to the photosensitiser protoporphyrin IX (PpIX). Following the exogenous administration of ALA, PpIX is generated intracellularly, which can then be activated by visible light for PDT treatment. ALA-PDT does exhibit a degree of intrinsic tumour selectivity owing to differing tumour levels of enzymes in the haem pathway (e.g. ferrochelatase) leading to higher tumour PpIX levels. The principal advantages of ALA-PDT are the short duration of skin photosensitivity and its efficacy using both topical and oral administration (Peng et al, 1997; Brown et al, 2004).

\footnotetext{
*Correspondence: Dr AJ MacRobert, National Medical Laser Centre, University College London, Charles Bell House, 67-73 Riding House St, London WIW 7EJ, UK; E-mail: a.macrobert@ucl.ac.uk

Received 25 November 2008; revised 12 January 2009; accepted 13 January 2009; published online 24 February 2009
}

A significant drawback of ALA-PDT is the fact that ALA is a zwitterion at physiological $\mathrm{pH}$ resulting in low lipid solubility and limiting passage through biological barriers such as cellular membranes. To overcome this problem, several chemical approaches have been attempted to improve the incorporation of ALA and also its selectivity. One approach has been to use more lipophilic ALA derivatives, such as alkyl or ethyleneglycol esters, which are potential substrates for cellular esterases (Kloek and Beijersbergen, 1996; Gaullier et al, 1997; Berger et al, 2000; Uehlinger et al, 2000), or different delivery systems including dendrimers (Battah et al, 2001, 2006; Di Venosa et al, 2006), or liposomes (Casas et al, 2002; Casas and Batlle, 2006). 5-Aminolaevulinic acid prodrug ester derivatives have been widely studied (Kloek and Beijersbergen, 1996; Peng et al, 1996; Gaullier et al, 1997; Kloek et al, 1998; Casas et al, 1999; Eleouet et al, 2000; Brunner et al, 2003; Lopez et al, 2004), in particular the methyl and hexyl ester derivatives, and approval has been granted for the treatment of actinic keratosis and basal cell carcinoma using the methyl ester derivative in Europe and Australia. The use of alkyl esters of ALA results in a nonspecific distribution of ALA in all cell types, but with an increased PpIX production (Webber et al, 1997; Uehlinger et al, 2000) in tumour cells. In this regard, Casas et al (1999) and Berger et al $(2000,2003)$ have conjectured that the 
incorporation of 5-ALA into a short peptide derivative would provide a suitable means of both facilitating transdermal delivery and also improved targeting to cancerous cells.

In an attempt to improve uptake and cell selectivity of ALA and its derivatives, we investigated PpIX formation and metabolism mechanisms using peptide ALA prodrugs that represent potential substrates for cell-surface and cytoplasmic peptidases and esterases. A recent investigation of ALA prodrugs showed that the L-enantiomer of Ac-Phe-ALA-Me, 1, was capable of delivering ALA to cells, with an enhancement of PpIX and PDT effectiveness, comparable with the results obtained with the hexyl ester derivative, ALA-Hex (Bourre et al, 2008). The ALA residue was masked on one side through a peptide bond and on the other side through an ester linkage, which were then cleaved enzymatically within the cells to liberate the ALA. We also showed that the D-enantiomer did not induce any PpIX production, which would be consistent with the stereospecific enzymatic cleavage acting only on the L-forms of such prodrugs.

In this study, we have focused on several ALA peptide derivatives using different amino acids and have studied the influence of structurural modification at the $\mathrm{N}$ terminus by changing the N-terminal blocking group. We then studied the metabolism mechanism involved in the release of ALA using class protease inhibitors and silencing of mammalian acylpeptide hydrolase activity (ACPH, EC 3.4.19.1) using small interfering RNA (siRNA) technology. Acylpeptide hydrolase, a member of the prolyl oligopeptidase family of serine peptidases, is an exopeptidase that removes acylated amino-acid residues from the $\mathrm{N}$ terminus of oligopeptides.

\section{MATERIALS AND METHODS}

\section{Chemicals}

5-Aminolaevulinic acid was purchased from Sigma-Aldrich Ltd (Gillingham, UK).
The structures of ALA peptide derivatives are shown in Figure 1. The synthesis of compounds 1-5 (Rogers et al, 2005) and 8 (Bourré et al, 2008) has already been reported. Compounds 6, 9 and 10 were synthesised according to the same procedure with minor modifications. Stock solutions of compounds 1 and 2 were prepared by dissolving at $10 \mathrm{~mm}$ in $0.01 \mathrm{M} \mathrm{HCl}$ and stored at $-20^{\circ} \mathrm{C}$. Compound 3 was dissolved at $100 \mathrm{~mm}$ in $0.1 \mathrm{M} \mathrm{HCl}$ solution and stored at $-20^{\circ} \mathrm{C}$.

\section{Cell culture}

The spontaneously transformed murine keratinocyte cell line, PAM212 (obtained from Professor R Groves, King's College, London), was cultured in RPMI-1640 medium (Gibco BRL, Life Technologies Ltd, Paisley, UK) containing L-glutamine ( $2 \mathrm{mM})$ and phenol red, supplemented with $10 \%$ foetal calf serum (FCS; SigmaAldrich Ltd) and penicillin and streptomycin $\left(500 \mathrm{U} \mathrm{ml}^{-1}\right.$ and $0.5 \mathrm{mg} \mathrm{ml}^{-1}$; Gibco BRL). The cells were routinely grown as monolayers in $75-\mathrm{cm}^{2}$ culture flasks (TPP; Helena Bioscience, Gateshead, UK) at $37^{\circ} \mathrm{C}, 5 \% \mathrm{CO}_{2}$ atmosphere until confluent.

\section{Porphyrin synthesis determination}

Cells were seeded into $\gamma$-sterilised 96-well plates (Orange Scientific, Triple Red Laboratory Technologies, Long Crendon, UK) at a density of $5 \times 10^{4}$ cells per well for $48 \mathrm{~h}$. After removing the culture medium, the wells were washed with PBS and incubated with freshly prepared solutions of ALA or ALA peptide derivatives 1-10: $0.1 \mathrm{ml}$ of serum-free medium containing varying prodrug concentrations was added to a designated series of wells. Each plate contained control wells with cells but without added drug for the determination of the background reading and reference wells containing cells incubated with the same ALA concentrations. For drug incubation, serum-free medium was used as serum is known to cause the release of PpIX from cells, thus resulting in the loss of fluorescence signal (Kloek et al, 1998).<smiles>[R5]CNC([R6])C(=O)NCC(=O)CCC(=O)O</smiles>

\begin{tabular}{|c|c|c|c|c|}
\hline Code & $\mathrm{R}_{1}$ & $\mathrm{R}_{2}$ & $\mathrm{R}_{3}$ & Name \\
\hline 1 & $\mathrm{H}_{3} \mathrm{COC}-$ & $-\mathrm{CH}_{2}-\mathrm{C}_{6} \mathrm{H}_{5}$ & $-\mathrm{CH}_{3}$ & Ac-Phe-ALA-Me \\
\hline 2 & $\mathrm{H}_{3} \mathrm{COC}-$ & $-\mathrm{H}$ & $-\mathrm{CH}_{3}$ & Ac-Gly-ALA-Me \\
\hline 3 & $\mathrm{H}_{3} \mathrm{COC}-$ & $-\mathrm{CH}_{3}$ & $-\mathrm{CH}_{3}$ & Ac-Ala-ALA-Me \\
\hline 4 & $\mathrm{H}_{3} \mathrm{COC}-$ & $-\mathrm{CH}\left(\mathrm{CH}_{3}\right)_{2}$ & $-\mathrm{CH}_{3}$ & Ac-Val-ALA-Me \\
\hline 5 & $\mathrm{H}_{3} \mathrm{COC}-$ & $-\mathrm{CH}_{2}-\mathrm{CH}\left(\mathrm{CH}_{3}\right)_{2}$ & $-\mathrm{CH}_{3}$ & Ac-Leu-ALA-Me \\
\hline 6 & $\mathrm{H}_{3} \mathrm{COC}-$ & $-\mathrm{CH}_{2} \mathrm{CH}_{2} \mathrm{SCH}_{3}$ & $-\mathrm{CH}_{3}$ & Ac-Met-ALA-Me \\
\hline 7 & $\mathrm{H}_{3} \mathrm{COC}-$ & $-\mathrm{CH}_{2}-\mathrm{C}_{6} \mathrm{H}_{5}$ & $-\mathrm{H}$ & Ac-Phe-ALA \\
\hline 8 & $\mathrm{H}-$ & $-\mathrm{CH}_{2}-\mathrm{C}_{6} \mathrm{H}_{5}$ & $-\mathrm{CH}_{3}$ & Phe-ALA-Me \\
\hline 9 & $\mathrm{H}-$ & $-\mathrm{CH}_{2}-\mathrm{C}_{6} \mathrm{H}_{5}$ & $-\mathrm{H}$ & Phe-ALA \\
\hline 10 & $\mathrm{C}_{6} \mathrm{H}_{5}-\mathrm{CH}_{2}-\mathrm{OCO}$ & $-\mathrm{CH}_{2}-\mathrm{C}_{6} \mathrm{H}_{5}$ & $-\mathrm{CH}_{3}$ & Z-Phe-ALA-Me \\
\hline
\end{tabular}

Figure I General structure of ALA peptide derivatives. 
The fluorescence signal from each well was measured with a spectrometer Perkin-Elmer LS 50B fluorescence spectrometer (Perkin Elmer, Beaconsfield, UK) using 410-nm excitation and $635-\mathrm{nm}$ emission wavelengths, with slit widths set to $10 \mathrm{~nm}$ and the internal $530 \mathrm{~nm}$ longpass filter used on the emission side; spectral scans were recorded between 600 and $750 \mathrm{~nm}$ to check for the presence of any porphyrins other than PpIX (Battah et al, 2006). The mean fluorescence intensity (expressed in arbitrary units) was calculated after subtraction of the control values. Intensity calibrations were performed using rhodamine B embedded in a Perspex disc as a standard.

\section{Photodynamic treatment}

Cells were seeded into 96-well plates at a density of approximately $2 \times 10^{4}$ cells per well. Following incubation for $48 \mathrm{~h}$, the cells were washed with PBS, and $0.1 \mathrm{ml}$ of solutions containing ALA, 1, 6, 7, 8 and 9 at $0.01 \mathrm{~mm}$ were added to their designated wells for 4 -h incubation periods. The plates were irradiated with a fluence of $2 \mathrm{~J} \mathrm{~cm}^{-2}$ using a LumiSource lamp (PCI Biotech, Oslo, Norway) that emits a uniform field of low-power blue light over an area of $14 \times 32 \mathrm{~cm}$. Peak output is around $420 \mathrm{~nm}$, which overlaps well with the PpIX Soret band. Immediately following irradiation, the medium was replaced and cells were incubated for a further $24 \mathrm{~h}$. Cell cytotoxicity was determined using the 3-(4,5-dimethylthiazol2-yl)-2,5-diphenyltetrazolium bromide (MTT) assay: cells were incubated with medium containing MTT $\left(1 \mathrm{mg} \mathrm{ml}^{-1}\right.$ dissolved in full RPMI-1640 medium) for $3 \mathrm{~h}$. The insoluble end product (formazan derivatives) was dissolved in $0.1 \mathrm{ml}$ of dimethylsulphoxide after removing the medium. Ultraviolet absorption was quantified at $570 \mathrm{~nm}$ using a 96-well plate reader (MR 700 Dynatech; Dynex, Worthing, UK). The mean cell survival was calculated for each prodrug at every concentration tested and expressed as a percentage of control (incubated with the compounds but not irradiated) cell survival values. For the determination of 'dark' toxicity of the compounds, well plates were prepared in the same manner as above but without irradiation.

\section{Peptidase activities}

Influence of protease inhibitors Evaluation of PpIX production by fluorescence recording in living cells, performed as described earlier above, was determined after incubation with a range of protease inhibitors. The protease inhibitors were added to cell cultures $10 \mathrm{~min}$ before adding ALA or compound 1 at $0.1 \mathrm{mM}$ and fluorescence increases were recorded. Protease inhibitors used are protease inhibitor cocktail $(1: 250)$, aprotinin (competitive serine protease inhibitor) $(20 \mu \mathrm{M})$, AEBSF (irreversible serine protease inhibitor) $(200 \mu \mathrm{M}), 2,2^{\prime}$-bipyridyl (metalloprotease inhibitor) $(20 \mu \mathrm{M})$, bestatin (metalloaminopeptidase inhibitor) $(100 \mu \mathrm{M})$, E64 (cysteine protease inhibitor) $(10 \mu \mathrm{M})$, leupeptin (trypsin-like protease and cysteine protease inhibitor) $(100 \mu \mathrm{M})$ and captopril (angiotensin-converting enzyme inhibitor) $(20 \mu \mathrm{M})$. Protease inhibitors were purchased from Sigma-Aldrich Ltd.

Acylpeptide hydrolase assay PAM212 cells were solubilised with Cellytic and centrifuged at $13000 \mathrm{~g}$ for $5 \mathrm{~min}$. The supernatant (cell lysate) was assayed for ACPH activity using $4 \mathrm{~mm}$ acetylalanine $p$-nitroanilide (AcApNA) (Kobayashi and Smith, 1987; Scaloni et al, 1992b; Yamaguchi et al, 1999) as substrate in $20 \mathrm{~mm}$ Tris-HCl (pH 7.4) (Scaloni et al, 1994). The influence of thiol reagent $\mathrm{pHMB}$ and histidine-modifying reagent $\mathrm{DEP}$ on $\mathrm{ACPH}$ activity was also assessed. The solution was kept at $37^{\circ} \mathrm{C}$ and the liberated $p$-nitroaniline from AcApNA was measured at $405 \mathrm{~nm}$ using a 96-well plate reader (MR 700 Dynatech) at 0, 10, 30, 60 and $120 \mathrm{~min}$.
The influence of ALA, Ac-Ala-Ala-Ala-Ala-OH and 1 on ACPH activity was evaluated as described above except that the cell lysate was preincubated with these compounds for $1 \mathrm{~h}$.

\section{Knockdown of ACPH protein expression with siRNA}

For each well transfected in 12-well plates, 60 pmol siRNA (ACPH siRNA; Invitrogen, Paisley, UK) was diluted in $200 \mu \mathrm{l}$ of serum-free Opti-MEM I Medium (Invitrogen). Then $2 \mu \mathrm{l}$ of Lipofectamine RNAiMAX was added to each well containing the diluted siRNA molecule and incubated for $20 \mathrm{~min}$ at room temperature.

PAM212 cells $\left(3 \times 10^{4}\right.$ per $\mathrm{ml}$ in RPMI with serum, without antibiotics) were seeded in 12-well plates ( $1 \mathrm{ml}$ per well) and allowed to grow for $72 \mathrm{~h}, 37^{\circ} \mathrm{C}, 5 \% \mathrm{CO}_{2}$, before experimentation. The PpIX synthesis was assessed after incubation with $0.5 \mathrm{~mm}$ of ALA or 1 during $4 \mathrm{~h}$, and then washed with PBS. One ml of CelLytic (Sigma-Aldrich Ltd) was added and incubated during $15 \mathrm{~min}$ at room temperature, and then the cells were mechanically scraped. Cell extracts were centrifuged at $1800 \mathrm{~g}$ for $10 \mathrm{~min}$ to remove the cell debris, and the supernatant containing the PpIX was collected. The fluorescence of extracted PpIX was measured as described earlier.

\section{Statistical analysis}

The results are displayed graphically, with error bars representing standard deviations. Differences are considered to be significant using the unpaired $t$-test.

\section{RESULTS}

\section{PpIX synthesis determination}

The PpIX produced by exposure to compounds 1-6, compared with ALA, is shown in Figure $2 \mathrm{~A}$ and B. At $0.01 \mathrm{~mm}$ (Figure 2A), ALA was not able to produce any measurable PpIX; however, a high amount of PpIX was produced with 1. Compounds 3, 5 and 6 also induced some PpIX production but to a lesser extent. However, compounds 2 and $\mathbf{4}$ were not able to induce measurable PpIX levels at this concentration. Using $0.1 \mathrm{~mm}$ (Figure 2B), the level of PpIX was enhanced by a factor 3.5 with 1,5 and 6 compared with ALA. Compounds 3 and 4 enhanced the PpIX production by a factor 1.5; however, 2 produced less PpIX compared with ALA.

\section{Fluorescence pharmacokinetics}

The kinetics of intracellular porphyrin fluorescence induced by exposure to compounds 1, 7-9 and ALA in the PAM212 cell line are shown in Figure $3 \mathrm{~A}$ and $\mathrm{B}$. Fluorescence spectral profiles were consistent with the production of PpIX, and peak emission at $635 \mathrm{~nm}$ was used for the pharmacokinetic measurements. Increasing porphyrin levels were observed with increasing incubation times from 2 to $6 \mathrm{~h}$. For the lowest concentration tested, $0.01 \mathrm{mM}$, no PpIX production was observed with ALA, 8 and 9 . However, 1 and 7 induced high levels of PpIX, 1 inducing the higher level regardless of the incubation time. When the concentration was increased to $0.1 \mathrm{~mm}$, all the compounds induced PpIX production, with a significant increase found with $\mathbf{1}$ and 7 . However, peptides 8 and 9, compounds without an acetyl group at the $\mathrm{N}$ terminus, induced less PpIX compared with ALA; these results were also observed in human epidermoid carcinoma A431 cells and colon carcinoma Caco-2 cells (data not shown). No significant difference was observed for 1 when the concentration was increased.

Figure 4A shows the results of experiments carried out with compound $10 v s 1$ and ALA, to observe the effect of the $\mathrm{Z}$ group at the $\mathrm{N}$ terminus instead of the acetyl group in compound 1 . No PpIX production was observed with 10 compared with ALA, 

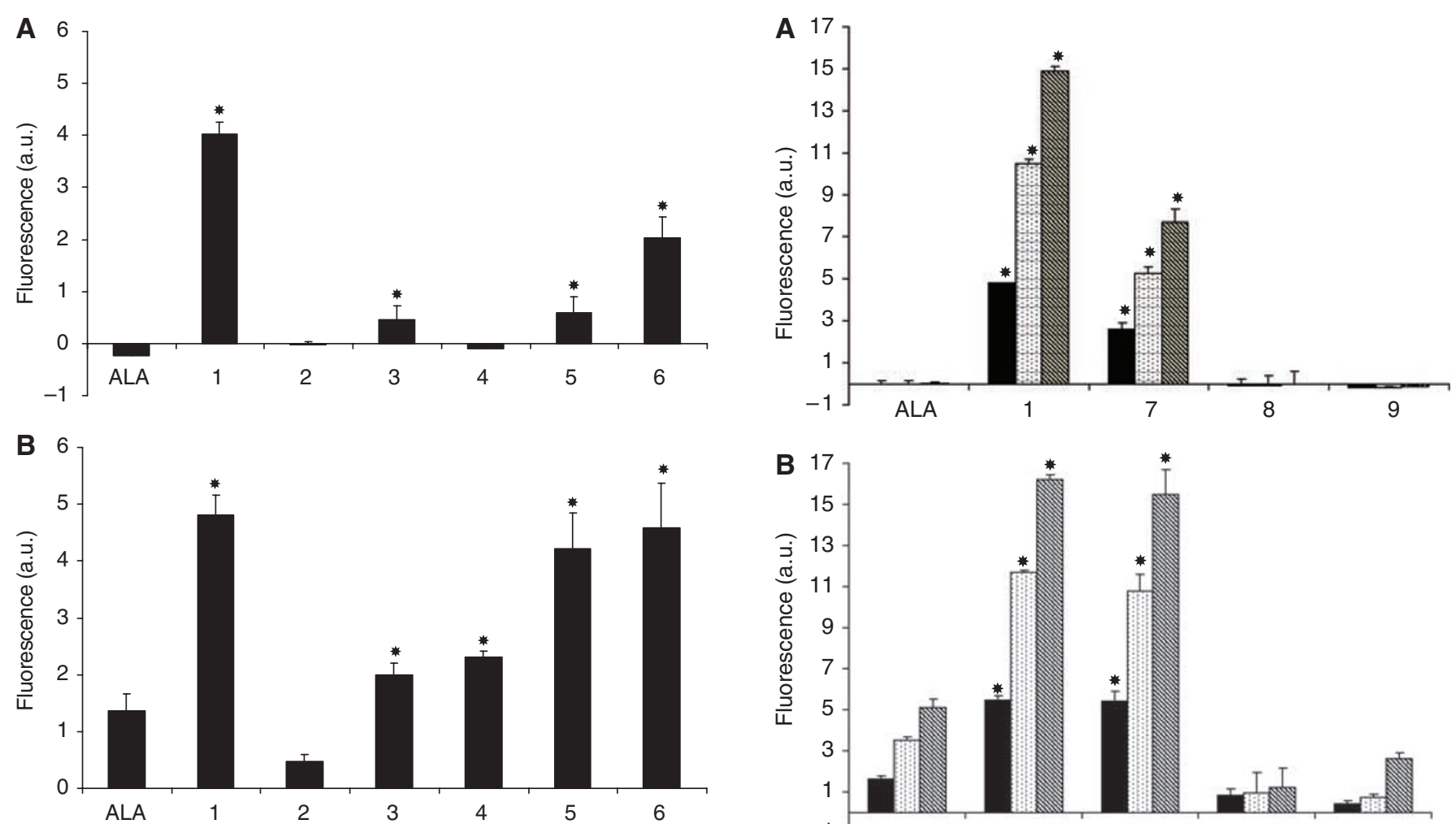

Figure 2 PpIX fluorescence in PAM 212 cells after incubation at $37^{\circ} \mathrm{C}$ for $4 \mathrm{~h}$ with $0.01 \mathrm{mM}(\mathbf{A})$ or $0.1 \mathrm{mM}(\mathbf{B})$ of ALA peptide derivatives $\mathbf{I}-\mathbf{6}$ and ALA. Error bars show standard deviations. ${ }^{*} P<0.01$ (ALA vs other compounds)

whatever the incubation time or the concentration used. In Figure $4 \mathrm{~B}$, the effect of the presence of the amino acid in the prodrug derivative was studied, and for this purpose, the molecule, Ac-ALA-Me, was synthesised. No PpIX production was observed with Ac-ALA-Me compared with ALA or 1, whatever the incubation time or the concentration used.

\section{Photodynamic treatment}

The phototoxicity was investigated after $4 \mathrm{~h}$ of incubation with $0.01 \mathrm{mM}$ of ALA, 1, 6, 7, 8 and 9. The percentage of cell survival with respect to control cells (without compounds) was calculated and plotted as shown in Figure 5. No dark toxicity was found for any of the compounds. Compounds 1, 6 and 7 exhibited a high phototoxicity with less than $5 \%$ cell survival. However, no phototoxicity was observed with ALA, 8 and 9, with 100, 82 and $84 \%$ of cell survival, respectively.

\section{Peptidase activities: acylpeptide hydrolase assay}

Influence of protease inhibitors To obtain information concerning the enzymatic activities involved in releasing free ALA from these precursors, we evaluated PpIX production after incubation with ALA or compound $\mathbf{1}$ in the presence of class-specific protease inhibitors (Figure 6): protease inhibitor cocktail, aprotinin, AEBSF, 2,2'-bipyridyl, bestatin, E64, leupeptin and captopril.

Aprotinin, bestatin, 2,2' -bipyridyl, E64, leupeptin and captopril had no significant effect. However, the PpIX production was reduced by serine protease inhibitor AEBSF.

Acylpeptide hydrolase assay To confirm ACPH activity in PAM212 cells, we tested the ACPH activity of cell lysates using AcApNA as a substrate (Scaloni et al, 1992b, 1994; Sharma and

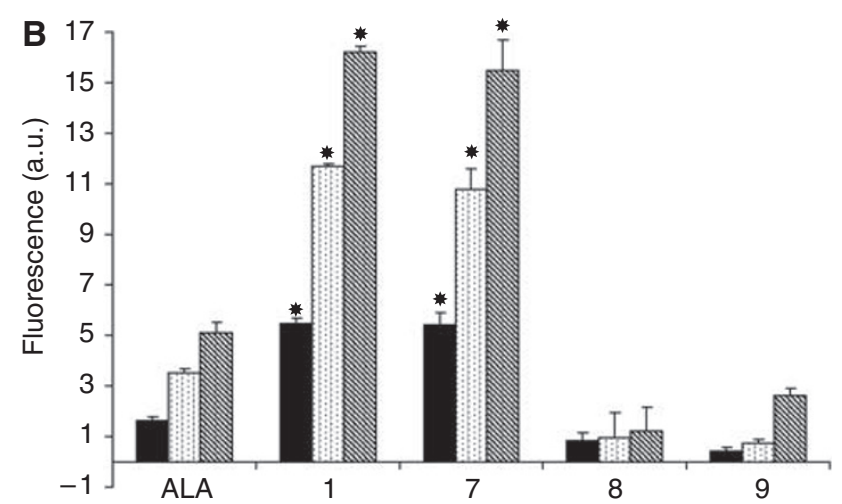

Figure $3 \mathrm{PplX}$ fluorescence in $\mathrm{PAM} 2 \mathrm{I} 2$ cells exposed at $37^{\circ} \mathrm{C}$ for 2 (-) 4 (露) and $6 \mathrm{~h}(\mathbb{N})$ with $0.01 \mathrm{mM}(\mathbf{A})$ or $0.1 \mathrm{mM}$ (B) of ALA, I, 7-9. Error bars show standard deviations. $* P<0.0$ I (ALA vs other compounds).

Ortwerth, 1993; Yamaguchi et al, 1999) and the influence of inhibitors. Acylpeptide hydrolase has earlier been reported to be inactivated with the thiol reagent pHMB (Scaloni et al, 1994) and histidine-modifying reagent DEP (Scaloni et al, 1992b). As shown in Figure 7A and B, the PAM212 cell lysate showed some ACPH activity in the absence of inhibitors. However, the ACPH activity was rapidly and completely inhibited by pHMB (Figure 7A) and moderately by DEP (Figure 7B).

To assess if our peptide prodrugs are potential substrates for $\mathrm{ACPH}$, we studied the influence of the concentration of the drug on AcApNA hydrolysis (Figure 7C). We evaluated the influence of ALA, phenylalanyl derivative 1 (the most efficient of the peptide derivatives) and Ac-Ala-Ala-Ala-Ala-OH, which is a substrate for ACPH (Krishna and Wold, 1992; Sokolik et al, 1994). 5-Aminolaevulinic acid exerted no significant influence on ACPH activity, whatever the concentration used. The ACPH substrate, Ac-Ala-Ala-Ala-Ala-OH, reduced the ACPH activity by 42 and $47 \%$, respectively, with 5 and $10 \mathrm{~mm}$. Compound 1 exhibited similar effects by a reduction of activity by 25 and $41 \%$ with 5 and $10 \mathrm{~mm}$. However, for lower concentrations tested, the activity was reduced by 22 and $28 \%$, respectively, with 0.5 and $1 \mathrm{~mm}$ with 1 ; no reduction of the activity was observed with Ac-Ala-Ala-Ala-Ala$\mathrm{OH}$ at these concentrations, showing that 1 has a higher affinity for ACPH compared with Ac-Ala-Ala-Ala-Ala-OH.

\section{Knockdown of ACPH protein expression with siRNA}

To further define the role of ACPH in the ALA peptide derivative hydrolysis, RNA interference for $\mathrm{ACPH}$ was employed by transfection of cells with the specific siRNA against murine ACPH mRNA (Figure 8). Inhibition of the ACPH protein expression by siRNA reduced the PpIX production significantly by $53 \%$ after incubation with compound 1 . However, when cells were incubated 
with ALA, the PpIX production was only reduced by $25 \%$. These results convincingly indicate that the expression of ACPH protein is involved in the hydrolysis of ALA peptide derivatives.
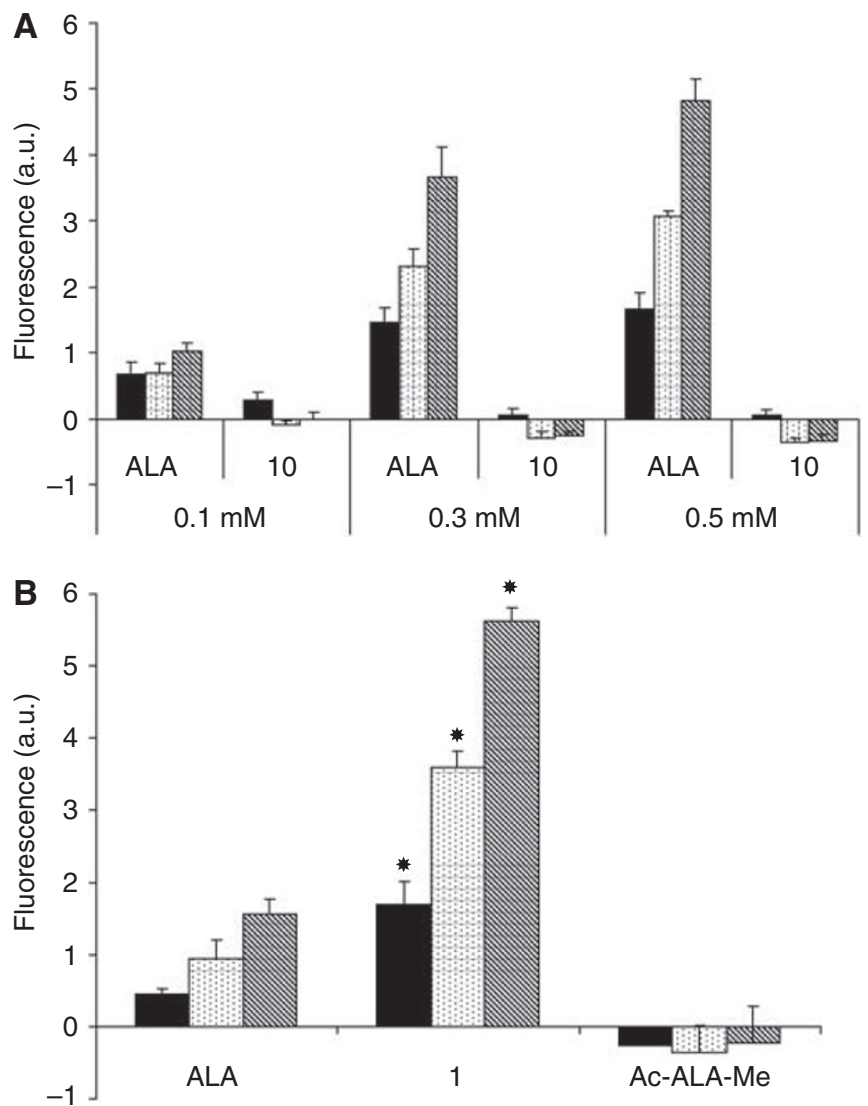

Figure 4 (A) PplX fluorescence in PAM2 12 cells exposed at $37^{\circ} \mathrm{C}$ for 2

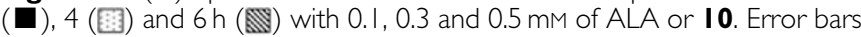
show standard deviations. $* P<0.01$ (ALA vs I0). (B) PpIX fluorescence in

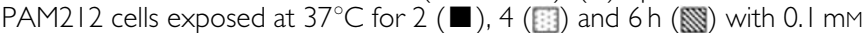
of ALA, I, Ac-ALA-Me. Error bars show standard deviations. $* P<0.01$ (ALA vs other compounds).

\section{DISCUSSION}

The targeted delivery of anticancer drugs to specific cell types, including photosensitisers in PDT, is of crucial importance for minimising treatment side effects. For the ALA prodrugs to exert a pharmacological effect, the derivatives must be able to reach the target sites at a sufficient concentration; this depends on the presence on the target cells of the necessary transport systems able to deliver them into the cytoplasm (Doring et al, 1998; Langer et al, 1999; Novotny et al, 2000; Rud et al, 2000; Irie et al, 2001) and their ability to undergo an efficient enzymatic hydrolysis to liberate ALA for the subsequent conversion to protoporphyrin IX (Peng et al, 1996).

A major challenge in ALA-PDT at the present time is the need to achieve a more effective penetration of ALA into target tissues or the cells of pathogenic organisms. A limitation to the use of ALA in PDT results from its low lipid solubility, a consequence of its zwitterionic character at physiological $\mathrm{pH}$ that leads to poor penetration through biological barriers such as cellular membranes. This problem has partly been addressed through the synthesis of lipophilic ester prodrugs that provide improved

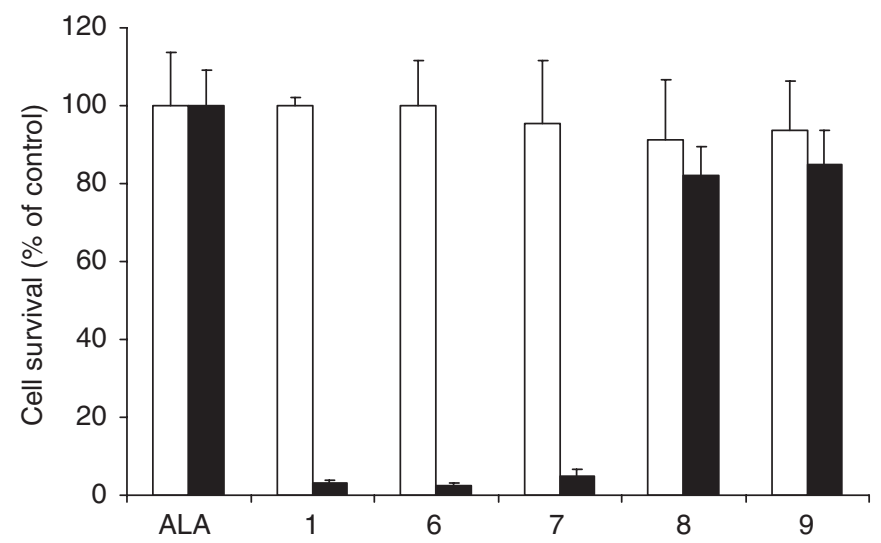

Figure 5 Toxicity $(\square)$ and phototoxicity $(\boldsymbol{\square})$ after incubation with ALA, I, 6, 7, 8 and $\mathbf{9}$ at $0.01 \mathrm{mM}$ in PAM 12 cell lines assessed by the MTT assay: cells were incubated with the compounds for $4 \mathrm{~h}$ and irradiated with blue light $\left(2 \mathrm{~J} \mathrm{~cm}^{-2}\right)$. Error bars show standard deviations.

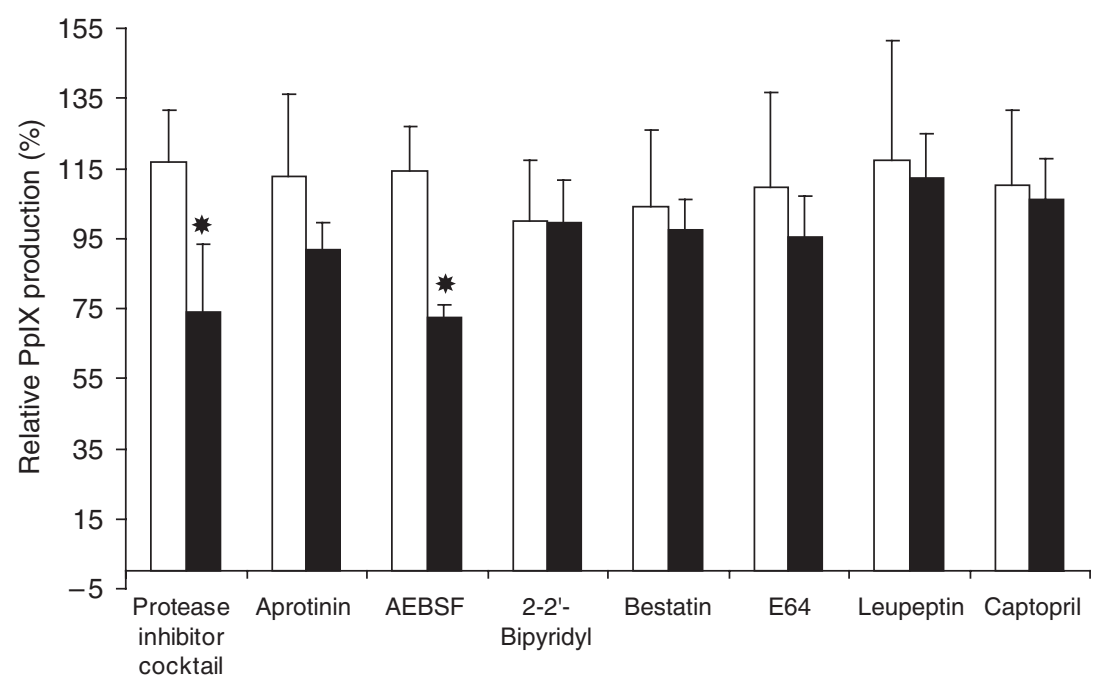

Figure 6 Relative PpIX production (\%) in PAM2I 2 cells exposed to class-specific protease inhibitors after $4 \mathrm{~h}$ of incubation with 0.1 mM of ALA ( $\square$ ) or I ( $)$ at $37^{\circ} \mathrm{C}$. Percentage was expressed compared with the cells treated with ALA or I without protease inhibitors. Error bars show standard deviations. $* P<0.05$. 
A
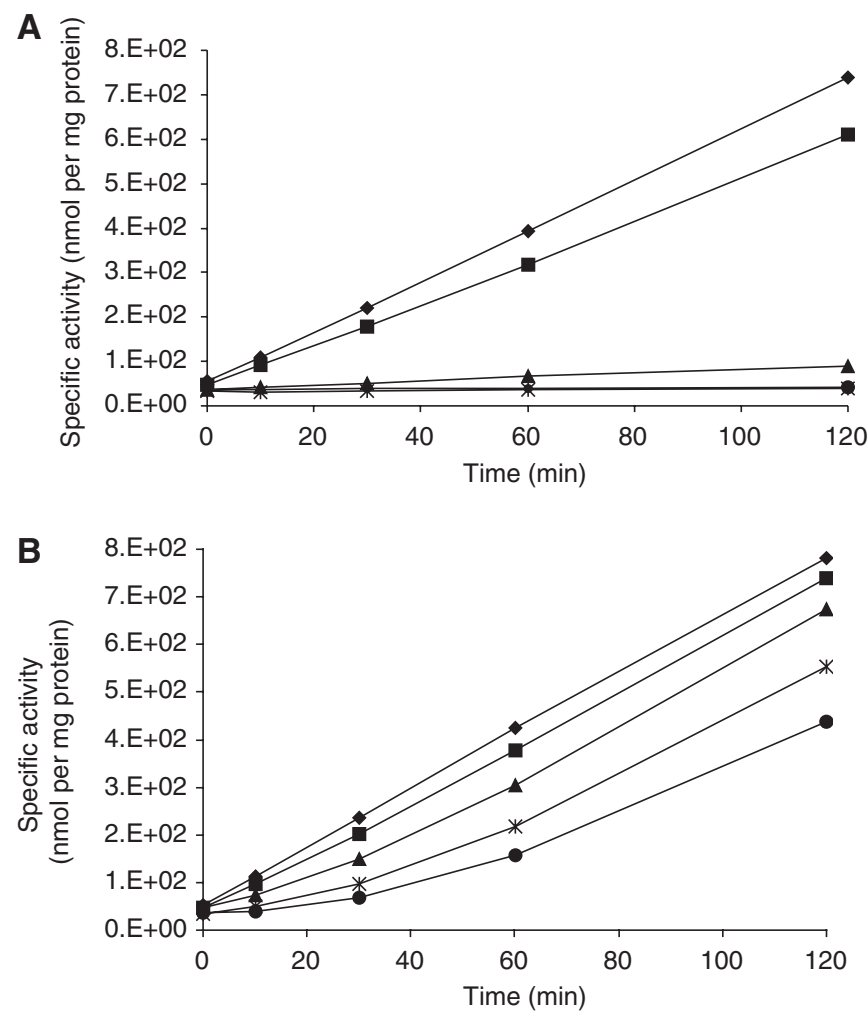

C

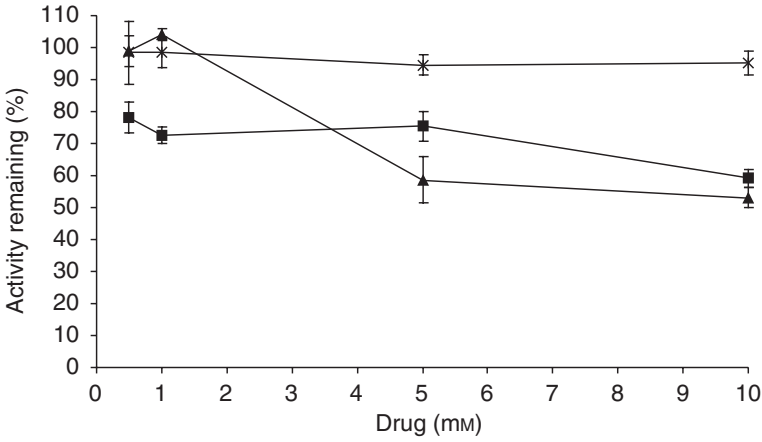

Figure 7 Inactivation of acylpeptide hydrolase by thiol reagent $\mathrm{pHMB}$ (A) and histidine-modifying reagent DEP (B). Cellular extracts were incubated with $0 \mathrm{mM}(\bullet), 0.01 \mathrm{mM}(\boldsymbol{\square}), 0.05 \mathrm{mM}(\boldsymbol{\Delta}), 0.2 \mathrm{mM}(*)$ and $0.5 \mathrm{mM}(\mathbf{O})$ of pHMB or DEP. (C) Influence of ALA (*), Ac-Ala-Ala-Ala$\mathrm{Ala}-\mathrm{OH}(\boldsymbol{\Lambda})$ and $\mathbf{I}(\boldsymbol{\square})$ on acylpeptide hydrolase activity. Cellular extracts were preincubated with a range of concentration of prodrugs during I h, then the enzyme activity was determined with AANA as substrate as described earlier after $30 \mathrm{~min}$.

cellular uptake and are metabolised into PpIX following the action of nonspecific intracellular esterases (Lopez et al, 2004). A more recent development concerns the preparation of peptide-based ALA prodrugs, and we (Casas et al, 1999; Rogers et al, 2005) and others (Berger et al, 2000, 2003) have described the synthesis and evaluation of short ALA peptide derivatives in which either the amino or the carboxyl functions of the latter are masked, thereby providing improved physical properties and the potential for cell line-specific ALA release, according to which peptidases are expressed. We have shown earlier the feasibility of using L-phenylalanyl-ALA derivatives (Bourré et al, 2008) to enhance intracellular porphyrin production and improve the efficacy of photodynamic treatment.

In this study, we investigated the properties of a larger number of ALA peptide derivatives containing different amino acids and studied the influence of structural modification in the form of the

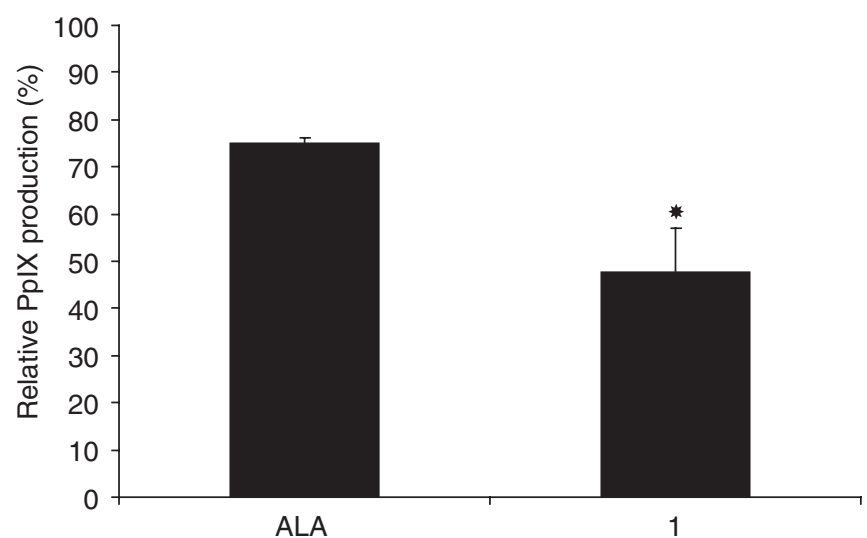

Figure 8 Relative PplX production (\%) in PAM2I2 cells treated with siRNA directed towards ACPH mRNA. Seventy-two hours after transfection, cells were incubated with $0.5 \mathrm{mM}$ of ALA or I during $4 \mathrm{~h}$ at $37^{\circ} \mathrm{C}$. Error bars show standard deviations. $* P<0.01$ (vs no transfected cells).

presence or absence of an $\mathrm{N}$-terminal blocking group, compared with ALA itself (Figure 1). The presence of the $N$-acetyl group at the $\mathrm{N}$ termini of compounds 1-7 prevents decomposition of the derivative at physiological $\mathrm{pH}$. Consequently, these peptide derivatives do not need to be prepared and then dissolved as hydrochloride salts, unlike ALA. We have also prepared the corresponding non-acetylated derivatives, 8 (L-Phe-ALA-Me) and the free acid 9 (L-Phe-ALA). However, these compounds show limited stability, presumably due to the cyclisation of the $\mathrm{N}$-terminal amino group of phenylalanine onto the carbonyl moiety of the ALA residue, generating a six-membered Schiff base intermediate that may react further (Berger et al, 2003), which therefore necessitates preparation just before the experiment.

The determination of protoporphyrin IX production (Figure 2) showed that compounds 1-6 were found to be capable of being taken up by cells and releasing ALA for subsequent conversion to PpIX, with a significant enhancement of PpIX production compared with ALA for compounds $1,6,5,4$ and 3, respectively.

The effect of modification of the prodrug structure at the $\mathrm{C}$ or $\mathrm{N}$ terminus on PpIX production, compared with ALA, was then studied. Fluorescence spectroscopy was employed to detect and quantify the PpIX accumulation induced by the compounds 1 and 7-10 vs ALA in the transformed keratinocyte PAM212 cell line. Compound 7 (Figure 3), corresponding to the free acid of compound 1, showed a significant increase compared with ALA, with a PpIX level comparable with compound $\mathbf{1}$. However, 8 and $\mathbf{9}$, compounds without an acetyl group at the $\mathrm{N}$ terminus, induced less PpIX compared with ALA. The acetyl group at the $\mathrm{N}$ terminus, therefore, seems to play an important role, in metabolic processes leading to the production of PpIX, whereas masking the $\mathrm{C}$ terminus as a methyl ester does not exert a major effect. In agreement with the fluorescence pharmacokinetic data, photodynamic treatment of cells incubated with ALA, 1, 6, 7, 8 and 9 (Figure 5) showed that the photocytotoxicity correlated with the PpIX fluorescence level described in Figure 3A. Following the illumination of cells incubated with compounds 1, 6 and 7, cell survival was significantly reduced (Figure 5) compared with equimolar ALA. However, ALA, 8 and $\mathbf{9}$ exhibited no phototoxicity in agreement with the lack of porphyrin produced by these compounds.

Substitution (compound 10) on the $\mathrm{N}$ terminus by a benzyloxycarbonyl (Z) group, instead of the acetyl group, abolished the activity of the compound with no PpIX production observed, as shown in Figure 4A. In pig skin explants, we have shown earlier 
(Bourré et al, 2008) that 1 was able to induce higher porphyrin fluorescence by a factor 3 compared with ALA at $0.2 \mathrm{~mm}$ drug concentration; however, once again no porphyrin production was found with the $\mathrm{Z}$ derivative (data not shown). Finally, the presence of the amino acid in the derivative was studied, and for this purpose the molecule, Ac-ALA-Me, was synthesised (Figure 4B). No PpIX production was observed with Ac-ALA-Me compared with ALA or 1, whatever the incubation time or the concentration used. In conclusion, the nature of the $\mathrm{N}$ terminus appears to play an important role in the efficacy of these compounds, which indicates that the release of the substituted amino acid intracellularly is probably conditioned by a specific enzymatic activity.

Berger et al (2000) have described the evaluation of several L-amino-acid ALA derivatives and their PpIX production in different cell lines (rat endothelial EC212, human endothelial HCEC and lung carcinoma A549 cells). Included in this study was compound 8, which showed high yields of PpIX in all cell lines compared with other neutral and charged amino-acid derivatives investigated. We have also observed PpIX production with this derivative in the PAM212 cell line, although it is far less efficient than the corresponding $\mathrm{N}$-terminally acetylated derivative 1 , which is moreover far more stable at physiological pH. Berger et al (2000) showed the involvement of aminopeptidase N/M activity in ALA release from 8 and other prodrugs in various cell lines. These enzymes, which are located both at the cell surface and in the cytoplasm, show a strong preference for substrates that contain neutral amino-acid residues at the $\mathrm{N}$ terminus. In agreement with our findings here, Berger et al (2000) observed no PpIX production in cells from peptide derivatives in which the $\mathrm{N}$ terminus was blocked with an alkoxycarbonyl group ( $t$-butoxycarbonyl, Boc). Such derivatives are not expected to be substrates for aminopeptidase N/M. Uncapped compounds 8 and 9, which are potential substrates for aminopeptidase N/M, showed low PpIX production. We did, however, find that PAM212 cells had APN/M activity using the specific substrates H-Ala- $\beta$ NA, H-Phe- $\beta$ NA and H-Leu- $\beta$ NA (data not shown), suggesting that the lack of PpIX production with 8 and 9 may be due to poor cellular uptake.

We also studied the influence of the aminopeptidase inhibitors (amastatin, bestatin and aminopeptidase $\mathrm{N}$ inhibitor) on PpIX production with 1 (data not shown), but none of them were able to reduce the PpIX production, confirming that the $N$-acetyl ALA peptide derivatives studied here should not be substrates for aminopeptidases and that these enzymes are not involved in the mechanism of ALA release from these ALA peptide derivatives. It is more probable that endopeptidases or exopeptidases, which can act on N-terminally acylated derivatives, are involved. On the basis of the results described here, it is probable that the $\mathrm{N}$-acetylated amino-acid residue is cleaved to release ALA or ALA-Me for conversion to PpIX. We hypothesised that the acylpeptidyl residue is most likely released by the acylpeptide hydrolase (ACPH, EC 3.4.19.1), a member of the prolyl oligopeptidase family of serine peptidases, and an exopeptidase that removes acylated amino-acid residues from the $\mathrm{N}$ terminus of oligopeptides.

To obtain further information concerning the enzymatic activities involved in releasing free ALA from these precursors, we evaluated PpIX production in the presence of class-specific protease inhibitors (Figure 6): protease inhibitor cocktail, aprotinin, AEBSF, 2,2'-bipyridyl, bestatin, E64, leupeptin and captopril. The PpIX production was reduced by the serine protease inhibitors, aprotinin and AEBSF.

The ACPH activity of the PAM212 cellular extract was then assessed using pAcNA as a substrate (Scaloni et al, 1992b, 1994; Sharma and Ortwerth, 1993; Yamaguchi et al, 1999). The PAM212 cell lysate showed some ACPH activity in the absence of inhibitors. However, the ACPH activity was rapidly and completely inhibited by $\mathrm{pHMB}$ (Figure 7A) and moderately by DEP (Figure 7B). The influence of preincubation of cell extracts with ALA peptide derivative on the $\mathrm{ACPH}$ activity was studied, showing that compound 1 induced a reduction of the activity by $41 \%$ at $10 \mathrm{~mm}$. These results were similar to those obtained with Ac-AlaAla-Ala-Ala-OH, an ACPH substrate, and are therefore consistent with the involvement of the serine protease ACOPH in ALA release from ALA-containing peptide derivatives.

The final functional argument to prove the causal relationship between ACPH expression/activity and ALA peptide derivative hydrolysis inducing the PpIX formation is now provided by the fact that the PpIX formation can be reduced by siRNA interference directed towards ACPH (Figure 8). Sequence-specific posttranscriptional gene silencing by double-stranded RNA (dsRNA), also called RNA interference, is conserved in a diverse variety of organisms (Gupta et al, 2004). RNA interference is mediated by siRNAs that are produced from long dsRNAs of exogenous or endogenous origin by an endonuclease of the ribonuclease-III type. The resulting siRNAs are 21-23 nucleotides long and are incorporated into a nuclease complex. After binding to the RNAinduced silencing complex, complementary mRNA is cleaved (Elbashir et al, 2001). Here, we described siRNA sequences effective in reducing ACPH expression on reverse transfection, leading to a significant PpIX reduction by $53 \%$ with compound 1 . These results confirm that the expression of ACPH protein is involved in the hydrolysis of the ALA peptide derivatives. Moreover, it is known that the enzyme is preferentially directed towards peptides with Ac-Ala- and Ac-Met-, and tolerates a variety of residues in the second position $\left(\mathrm{P}_{1^{\prime}}\right)$ (Jones and Manning, 1988; Radhakrishna and Wold, 1989; Krishna and Wold, 1992; Sokolik et al, 1994; Raphel et al, 1999). This is consistent with the results obtained with compound 6 corresponding to methionyl derivative, which shows a higher PpIX enhancement compared with the other derivatives, apart from 1, which also induces similar levels of PpIX. Compound 3, corresponding to the alanyl derivative, induced a PpIX enhancement compared with ALA but not as high as that of the methionyl or phenylalanyl derivative. However, this result does not reflect the ACPH substrate specificity described in the literature (Kobayashi and Smith, 1987; Krishna and Wold, 1992; Sokolik et al, 1994), in which it was found that Ac-Ala-Ala-Ala is the substrate that exhibits the highest hydrolysis efficiency. The hydrolysis parameters were generally determined on specific sequences by studying the influence of the position of one amino acid in the sequence on the hydrolysis rate. In the case of the compounds studied here, no corresponding data are available on the ACPH activity towards peptides including 5-ALA, which mimic Gly-Gly dipeptides, that is with a general sequence Ac-aa-Gly-Gly. These discrepancies need to be examined in terms of the sequence in which the presumed specificity-determining amino acids were displayed in the different substrates, and it would be an oversimplification to merely state that $\mathrm{ACPH}$ requires a given residue in position $\mathrm{P} 1, \mathrm{P}^{\prime}, \mathrm{P}^{\prime}$ and so on. One also has to consider how the activity will be interdependent on the presence of these residues in conjunction with all the other constituents of the peptide substrate. A further potentially important factor is that owing to the presence of the phenyl group, the phenylalanyl derivative is more lipophilic than the alanyl derivative, which should enhance the relative cellular uptake of the phenylalanyl derivative and therefore the measured porphyrin level.

In conclusion, the results in this study provide further evidence that the conjugation of ALA with specific amino acids is a promising approach for inducing enhanced intracellular porphyrin production for photodynamic therapy. As peptidase expression is generally different between normal and tumour cells or tissues, there is the possibility of more specific targeting, particularly by modulating the $\mathrm{N}$-terminal portion. Our derivatives showed a specific affinity for $\mathrm{ACPH}$, an enzyme the expression of which is higher in tumour cells compared with normal cells (Schoenberger et al, 1986). Indeed, although ACPH activity is practically absent in A549 small-cell lung carcinoma cells (Scaloni et al, 1992a), we were still able to observe low levels of PpIX production after incubation with compound 1 (data 
not shown). The peptide prodrugs described herein may be suitable for both topical use (e.g. for bladder and cervical cancers in addition to basal cell carcinomas) and for systemic administration in view of their low inherent toxicity (Bourré et al, 2008) compared with the hexyl ester of ALA. Further studies to optimise peptide-based ALA delivery are currently in progress using more complex ALA-containing amino-acid sequences and cell-penetrating peptide carriers (Dixon et al, 2007).

\section{REFERENCES}

Battah S, O'Neill S, Edwards C, Balaratnam S, Dobbin P, MacRobert AJ (2006) Enhanced porphyrin accumulation using dendritic derivatives of 5-aminolaevulinic acid for photodynamic therapy: an in vitro study. Int $J$ Biochem Cell Biol 38: $1382-1392$

Battah SH, Chee CE, Nakanishi H, Gerscher S, MacRobert AJ, Edwards C (2001) Synthesis and biological studies of 5-aminolevulinic acidcontaining dendrimers for photodynamic therapy. Bioconjug Chem 12: $980-988$

Berger Y, Greppi A, Siri O, Neier R, Juillerat-Jeanneret L (2000) Ethylene glycol and amino acid derivatives of 5 -aminolevulinic acid as new photosensitizing precursors of protoporphyrin IX in cells. J Med Chem 43: $4738-4746$

Berger Y, Ingrassia L, Neier R, Juillerat-Jeanneret L (2003) Evaluation of dipeptide-derivatives of 5 -aminolevulinic acid as precursors for photosensitizers in photodynamic therapy. Bioorg Med Chem 11: $1343-1351$

Bonnett R (1995) Photosensitizers of the porphyrin and phthalocyanine series for photodynamic therapy. Chem Soc Rev 24: 19-33

Bourré L, Giuntini F, Wilson M, Eggleston IM, MacRobert AJ (2008) 5-Aminolaevulinic acid peptide prodrugs enhance photosensitisation for photodynamic therapy. Mol Cancer Ther 7: 1720-1729

Brown SB, Brown EA, Walker I (2004) The present and future role of photodynamic therapy in cancer treatment. Lancet Oncol 5: 497-508

Brunner H, Hausmann F, Knuechel R (2003) New 5-aminolevulinic acid esters - efficient protoporphyrin precursors for photodetection and photodynamic therapy. Photochem Photobiol 78: 481-486

Casas A, Batlle A (2006) Aminolevulinic acid derivatives and liposome delivery as strategies for improving 5-aminolevulinic acid-mediated photodynamic therapy. Curr Med Chem 13: 1157-1168

Casas A, Batlle AMD, Butler AR, Robertson D, Brown EH, MacRobert A, Riley PA (1999) Comparative effect of ALA derivatives on protoporphyrin IX production in human and rat skin organ cultures. Br J Cancer 80 $1525-1532$

Casas A, Perotti C, Saccoliti M, Sacca P, Fukuda H, Batlle AM (2002) ALA and ALA hexyl ester in free and liposomal formulations for the photosensitisation of tumour organ cultures. Br J Cancer 86: 837-842

Di Venosa GM, Casas AG, Battah S, Dobbin P, Fukuda H, MacRobert AJ, Batlle A (2006) Investigation of a novel dendritic derivative of 5aminolaevulinic acid for photodynamic therapy. Int J Biochem Cell Biol 38: $82-91$

Dixon MJ, Bourre L, MacRobert AJ, Eggleston IM (2007) Novel prodrug approach to photodynamic therapy: Fmoc solid-phase synthesis of a cell permeable peptide incorporating 5-aminolaevulinic acid. Bioorg Med Chem Lett 17: $4518-4522$

Doring F, Walter J, Will J, Focking M, Boll M, Amasheh S, Clauss W, Daniel H (1998) Delta-aminolevulinic acid transport by intestinal and renal peptide transporters and its physiological and clinical implications. J Clin Invest 101: $2761-2767$

Elbashir SM, Lendeckel W, Tuschl T (2001) RNA interference is mediated by 21- and 22-nucleotide RNAs. Genes Dev 15: 188-200

Eleouet S, Rousset N, Carre J, Bourre L, Vonarx V, Lajat Y, Beijersbergen van Henegouwen GM, Patrice T (2000) In vitro fluorescence, toxicity and phototoxicity induced by delta-aminolevulinic acid (ALA) or ALA-esters. Photochem Photobiol 71: 447-454

Gaullier JM, Berg K, Peng Q, Anholt H, Selbo PK, Ma LW, Moan J (1997) Use of 5-aminolevulinic acid esters to improve photodynamic therapy on cells in culture. Cancer Res 57: $1481-1486$

Gupta S, Schoer RA, Egan JE, Hannon GJ, Mittal V (2004) Inducible, reversible, and stable RNA interference in mammalian cells. Proc Nat Acad Sci USA 101: 1927-1932

\section{ACKNOWLEDGEMENTS}

We acknowledge the assistance of Noreen Farooqui in carrying out this study and materials provided by Dr Sandy Mosse. We are grateful to Dr Marilena Loizidou for helpful discussions. This study was supported by Biotechnology and Biological Sciences Research Council grants BBD0127831 (IM Eggleston) and BBD0113291 (AJ MacRobert, M Wilson).

Irie M, Terada T, Sawada K, Saito H, Inui K (2001) Recognition and transport characteristics of nonpeptidic compounds by basolateral peptide transporter in Caco-2 cells. J Pharmacol Exp Ther 298: 711-717

Jones WM, Manning JM (1988) Substrate specificity of an acylaminopeptidase that catalyzes the cleavage of the blocked amino termini of peptides. Biochim Biophys Acta 953: $357-360$

Kloek J, Akkermans W, van Henegouwen GMJB (1998) Derivatives of 5-aminolevulinic acid for photodynamic therapy: enzymatic conversion into protoporphyrin. Photochem Photobiol 67: 150-154

Kloek J, Beijersbergen vH (1996) Prodrugs of 5-aminolevulinic acid for photodynamic therapy. Photochem Photobiol 64: 994-1000

Kobayashi K, Smith JA (1987) Acyl-peptide hydrolase from rat liver. Characterization of enzyme reaction. J Biol Chem 262: 11435-11445

Krishna RG, Wold F (1992) Specificity determinants of acylaminoacylpeptide hydrolase. Protein Sci 1: 582-589

Langer S, Abels C, Botzlar A, Pahernik S, Rick K, Szeimies RM, Goetz AE (1999) Active and higher intracellular uptake of 5-aminolevulinic acid in tumors may be inhibited by glycine. J Invest Dermatol 112: $723-728$

Lopez RF, Lange N, Guy R, Bentley MV (2004) Photodynamic therapy of skin cancer: controlled drug delivery of 5-ALA and its esters. Adv Drug Deliv Rev 56: 77-94

Novotny A, Xiang J, Stummer W, Teuscher NS, Smith DE, Keep RF (2000) Mechanisms of 5 -aminolevulinic acid uptake at the choroid plexus. J Neurochem 75: $321-328$

Peng Q, Moan J, Warloe T, Iani V, Steen HB, Bjorseth A, Nesland JM (1996) Build-up of esterified aminolevulinic-acid-derivative-induced porphyrin fluorescence in normal mouse skin. J Photochem Photobiol B 34: $95-96$

Peng Q, Warloe T, Berg K, Moan J, Kongshaug M, Giercksky KE, Nesland JM (1997) 5-aminolevulinic acid-based photodynamic therapy - clinical research and future challenges. Cancer 79: 2282-2308

Radhakrishna G, Wold F (1989) Purification and characterization of an $\mathrm{N}$-acylaminoacyl-peptide hydrolase from rabbit muscle. J Biol Chem 264: $11076-11081$

Raphel V, Giardina T, Guevel L, Perrier J, Dupuis L, Guo XJ, Puigserver A (1999) Cloning, sequencing and further characterization of acylpeptide hydrolase from porcine intestinal mucosa. Biochim Biophys Acta 1432: $371-381$

Rogers LMA, McGivern PG, Butler AR, MacRobert AJ, Eggleston IM (2005) An efficient synthesis of 5-aminolaevulinic acid (ALA)-containing peptides for use in photodynamic therapy. Tetrahedron 61: 6951-6958

Rud E, Gederaas O, Hogset A, Berg K (2000) 5-aminolevulinic acid, but not 5 -aminolevulinic acid esters, is transported into adenocarcinoma cells by system BETA transporters. Photochem Photobiol 71: 640-647

Scaloni A, Barra D, Jones WM, Manning JM (1994) Human acylpeptide hydrolase. Studies on its thiol groups and mechanism of action. $J$ Biol Chem 269: $15076-15084$

Scaloni A, Jones W, Pospischil M, Sassa S, Schneewind O, Popowicz AM, Bossa F, Graziano SL, Manning JM (1992a) Deficiency of acylpeptide hydrolase in small-cell lung carcinoma cell lines. J Lab Clin Med 120: $546-552$

Scaloni A, Jones WM, Barra D, Pospischil M, Sassa S, Popowicz A, Manning LR, Schneewind O, Manning JM (1992b) Acylpeptide hydrolase: inhibitors and some active site residues of the human enzyme. $J$ Biol Chem 267: $3811-3818$

Schoenberger OL, Schwobel H, Ebert W (1986) $N$-acetylalanine aminopeptidase activity in normal and tumour cells. J Clin Chem Clin Biochem 24: $375-378$

Sharma KK, Ortwerth BJ (1993) Bovine lens acylpeptide hydrolase. Purification and characterization of a tetrameric enzyme resistant to urea denaturation and proteolytic inactivation. Eur J Biochem 216: 631 -637 
Sokolik CW, Liang TC, Wold F (1994) Studies on the specificity of acetylaminoacyl-peptide hydrolase. Protein Sci 3: 126-131

Uehlinger P, Zellweger M, Wagnieres G, Juillerat-Jeanneret $\mathrm{L}$, van den $\mathrm{BH}$, Lange N (2000) 5-Aminolevulinic acid and its derivatives: physical chemical properties and protoporphyrin IX formation in cultured cells. J Photochem Photobiol B 54: 72-80
Webber J, Kessel D, Fromm D (1997) Side effects and photosensitization of human tissues after aminolevulinic acid. J Surg Res 68: $31-37$

Yamaguchi M, Kambayashi D, Toda J, Sano T, Toyoshima S, Hojo H (1999) Acetylleucine chloromethyl ketone, an inhibitor of acylpeptide hydrolase, induces apoptosis of U937 cells. Biochem Biophys Res Commun 263: $139-142$ 